\title{
Monoclonal Antibody TRK-950
}

National Cancer Institute

\section{Source}

National Cancer Institute. Monoclonal Antibody TRK-950. NCI Thesaurus. Code C142826.

A proprietary monoclonal antibody targeting an as of yet undisclosed tumor-associated antigen (TAA), with potential antineoplastic activity. Although the mechanism of action has not been elucidated presumably monoclonal antibody TRK-950 binds to a specific TAA on the cell surface of tumor cells and may induce complement-dependent cytotoxicity (CDC) and antibody-dependent cell-mediated cytotoxicity (ADCC). This may lead to the death of tumor cells expressing the TAA. 